\title{
KAITAN PERUBAHAN TUTUPAN LAHAN DAN AKTIVITAS MASYARAKAT DENGAN KUALITAS AIR SUNGAI SUBAYANG, KABUPATEN KAMPAR, TAHUN 2017- 2020
}

\author{
Rizka Putri Ade Sami ${ }^{1}$, Nurul Qomar ${ }^{2 *}$ Darmadi $^{3}$ \\ ${ }^{1)}$ Email: rizkaputri97@gmail.com \\ ${ }^{2 *}$ E-mail: nqomar@lecturer.unri.ac.id \\ ${ }^{3)}$ E-mail : darmadiahmad74@gmail.com
}

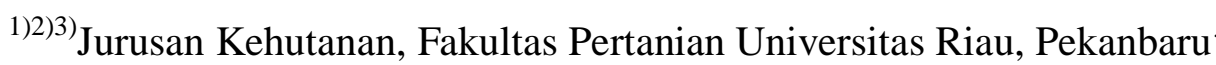

\begin{abstract}
The natural resource that humans really need is water. Availability of fresh water or clean water experiences scarcity along with population growth. One source of fresh water of concern is the river.The research aims to determine the conditions of land cover, community activities and to analyze its correlation to the quality of water in Subayang river during 2017-2020. This qualitative descriptive research was conducted in the sub-Watershed Area (DAS) of Subayang, Kampar Kiri Hulu District on June - August 2021. The primary data of the study were obtained through field observations and interviews. For secondary data sourced from land cover data 2017-2020 by the Ministry of Environment and Forestry and water quality measurement of Subayang river by the Fresh Water and Fisheries Team of WWF Indonesia-Central Sumatra. The sample observations from upstream to downstream are in the villages of Aur Kuning, Batu Songgan and Tanjung Belit. Determination of the quality status of river water quality is analyzed by using the Pollution Index (IP) approach based on the reference of the Ministry of Environment No. 115/ 2003 with the determination of quality standards based on Government Regulation No.22/2021. The results of measuring temperature, river flow velocity (current), turbidity, dissolved oxygen, and $\mathrm{pH}$ in 3 observation areas from 2017-2020 showed the Subayang's river was in good quality with a Pollution Index (IP) ranging from 0.27- 0.80 (quality standards). The land cover which is still dominated by forest (97-99.15\%), the use of forests and rivers based on local wisdom, as well as the improvement in waste management and MCK's activities by the community affect the condition of the waters of the Subayang river which is maintained its quality with IP values that meet the quality standard values ( good condition).
\end{abstract}

Keywords: Communnity Activities; Land Cover; Subayang River; Water Quality.

\section{ABSTRAK}

Sumber daya alam yang sangat dibutuhkan manusia adalah air. Ketersediaan air tawar atau air bersih mengalami kelangkaan seiring dengan pertumbuhan penduduk. Salah satu sumber air tawar yang menjadi perhatian adalah sungai. Penelitian ini bertujuan untuk mengetahui kondisi tutupan lahan, aktivitas masyarakat serta menganalisis kaitannya dengan kualitas perairan Sungai Subayang tahun 2017-2020. Penelitian ini dilaksanakan di wilayah Sub-sub Daerah Aliran Sungai (DAS) Subayang, Kecamatan Kampar Kiri Hulu, Kabupaten Kampar pada Juni-Agustus 2021. Data primer penelitian didapatkan melalui observasi lapangan dan wawancara. Data sekunder meliputi data tutupan lahan bersumber dari KLHK dan data pengkuran kualitas air Sungai Subayang 2017-2020 bersumber dari Tim Fresh Water and Fisheries WWF Indonesia- Central Sumatra. Sampel pengamatan dari bagian hulu ke hilir berada di desa Aur Kuning, Batu Songgan 
dan Tanjung Belit. Penentuan status mutu kualitas air sungai dianalisis menggunakan pendekatan Indeks Pencemaran (IP) berdasarkan Peraturan Menteri Lingkungan Hidup Nomor 115 tahun 2003, dan penentuan baku mutu berdasarkan Peraturan Pemerintah Nomor 22 Tahun 2021. Hasil penelitian menunjukkan bahwa berdasarkan parameter suhu, kecepatan aliran sungai (arus), kekeruhan, oksigen terlarut, dan pH dari tahun 2017-2020, air Sungai Subayang berada pada kualitas baik dengan Indeks Pencemaran (IP) berkisar 0,27-0,80 (memenuhi nilai baku mutu kelas 2). Kualitas perairan yang baik tersebut berkaitan dan dipengaruhi oleh kondisi tutupan lahan yang masih didominasi hutan (97-99,15\%), praktek pemanfaatan hutan dan sungai berbasis kearifan lokal, serta mulai membaiknya pengelolaan limbah dan aktivitas MCK oleh masyarakat.

Kata Kunci: Aktivitas Masyarakat; Kualitas Air; Sungai Subayang; Tutupan Lahan.

\section{PENDAHULUAN}

Komponen air di bumi terdiri atas $96 \%$ air laut, $1 \%$ air bawah tanah, $1 \%$ air danau dan sungai serta 2\% merupakan gletser (WWF, 2014). Namun, ketersediaan air tawar atau air bersih mengalami kelangkaan seiring dengan pertumbuhan penduduk. Menurut (Kalogirou, 2005), total konsumsi air yang dapat digunakan untuk kebutuhan rumah tinggal hanya sebesar $10 \%$. Terbatasanya kuantitas dan kualitas air mengharuskan pengelolaan dan pemanfaatan sumber air secara benar dan bijaksana.

Sungai Subayang yang terletak di kecamatan Kampar Kiri Hulu merupakan Sub DAS Sungai Kampar yang mengalir di tengah-tengah Suaka Margasatwa Bukit Rimbang-Bukit Baling. Sungai Subayang ini merupakan sumber air utama masyarakat di sekitar bantaran sungai (Syuhada et al., 2016). Selain dimanfaatkan untuk kebutuhan rumah tangga, Sungai Subayang juga menjadi sumber perekonomian masyarakat melalui hasil tangkapan ikan, sungai ini juga berfungsi sebagai jalur transportasi, penghubung antar desa serta jalur menuju destinasi ekowisata air terjun Batu Dinding dan Suaka Margasatwa Bukit Rimbang Bukit Baling (Firdaus \& Elfis, 2017).

Berdasarkan penelitian Kelompok Kerja Air Minum dan Penyehatan Lingkungan (POKJA AMPL) (2005) dan Amalia dan Sugiri (2014), penggundulan hutan dan alih fungsi lahan hutan primer menjadi lahan monokultur berdampak pada kualitas dan ketersedian air bersih sungai karena berdampak pada kekeruhan dan suhu air sungai. Sementara, Yapeka dan organisasi lingkungan lainnya (2017) menyatakan bahwa terdapat sejumlah aktivitas ekowisata di sepanjang bantaran Sungai Subayang, seperti air terjun batu dinding, camping ground Subayang, jembatan gantung dan sebagainya, serta mulai beroperasinya laboratorium air tawar WWF tahun 2017. Hal ini dapat meningkatkan masyarakat luar yang datang berkunjung ke Subayang sehingga akan meningkatkan aktivitas masyarakat di sepanjang bantaran sungai yang dikhawatirkan mempengaruhi kualitas air Sungai Subayang. 
Melihat pentingnya air Sungai Subayang bagi masyarakat sekitar dan makhluk hidup lainnya serta mulai terjadinya perubahan tutupan lahan serta peningkatan aktivitas masyarakat di sekitar sungai, maka peneliti tertarik untuk melakukan penelitian "Kaitan Perubahan Tutupan Lahan dan Aktivitas Masyarakat dengan Kualitas Air Sungai Subayang Kec. Kampar Kiri Hulu, Kampar, Tahun 2017-2020". Penelitian ini bertujuan menganalisis keterkaitan pola tutupan lahan dan aktivitas masyarakat dengan kualitas perairan Sungai Subayang pada tahun 2017-2020.

\section{METODE PENELITIAN}

Penelitian ini dilaksanakan di wilayah Sub-sub DAS Subayang, Kecamatan Kampar Kiri Hulu, Kabupaten Kampar. Sampel permukiman masyarakat dipilih dari wilayah hulu, tengah dan hilir, yakni Desa Aur Kuning, Batu Sanggan dan Desa Tanjung Belit. Penelitian dilaksanakan pada bulan Juni-Agustus 2021.

Pendekatan penelitian berupa deskriptif kualitatif. Data primer didapatkan melalui hasil observasi lapangan dan wawancara dengan masyarakat dan pemerintah desa mengenai aktivitas masyarakat dan peraturan yang terkait dengan pemanfaatan air Sungai Subayang dari tahun 2017 hingga 2020. Aktivitas masyarakat yang diamati meliputi aktivitas ekonomi, aktivitas rumah tangga dan aktivitas wisata. Kriteria responden yaitu masyarakat yang melakukan aktivitas ekonomi, rumah tangga dan ekowisata yang berhubungan langsung dengan Sungai Subayang. Jumlah responden per desa ditentukan secara proporsional yaitu didasarkan pada perbandingan jumlah rumah tangga per desa dengan total jumlah rumah tangga tiga desa sampel. Total jumlah responden adalah 42 orang, ditentukan berdasarkan rumus Slovin dengan batas toleransi kesalahan sebesar 15 \%. Data sekunder dalam penelitian ini berupa 1) Peta tutupan lahan di Sub-sub DAS Subayang 2017-2020 yang bersumber dari Dirjen Planologi Kehutanan dan Lingkungan Hidup (KLHK), 2) data hasil pengukuran kualitas air sungai Subayang yang bersumber dari Tim Fresh Water and Fisheries WWF Indonesia-Central Sumatra dengan parameter kualitas air meliputi: (a) Parameter Fisik berupa Suhu, Kekeruhan dan Kecepatan Aliran Air; dan (b) Parameter Kimia berupa pH dan kandungan oksigen terlarut. Penentuan sampel dilakukan secara purposive sampling dengan merujuk pada tata cara pengambilan contoh kualitas air Standar Nasional Indonesia (SNI) 03-07162004, yaitu:

a. Kualitas air sebelum adanya pengaruh kegiatan manusia yaitu pada lokasi hulu sungai yang dimaksudkan untuk mengetahui kualitas air secara alamiah sebagai base line station.

b. Pengaruh kegiatan manusia terhadap kualitas air dan pengaruhnya untuk pemanfaatan tertentu. Lokasi ini dimaksudkan untuk mengetahui pengaruh kegiatan manusia yang disebut "impact 
station".

c. Sumber-sumber pencemaran yang dapat memasukkan zat-zat yang berbahaya kedalam sumber air. Lokasi ini dimaksudkan untuk mengetahui sumber penyebaran bahan-bahan yang berbahaya, sehingga dapat ditanggulangi.

Berdasarkan pertimbangan tersebut, maka sampel wilayah hulu, tengah dan hilir dalam penelitian ini secara berurutan berada di Desa Aur Kuning, Desa Batu Sanggan dan Desa Tanjung Belit. Desa Aur Kuning sebagai bagian hulu merupakan desa dengan pengaruh aktivitas masyarakat yang paling minim, Desa Batu Sanggan adalah desa dengan aktivitas masyarakat yang sudah mulai berdampak pada kualitas air serta Desa Tanjung Belit sebagai wilayah terhilir menjadi desa yang diperkirakan memberikan dampak perubahan kualitas air sungai karena merupakan desa dengan pemukiman padat penduduk dan pola perubahan aktivitas dan penggunaan lahan (Susanto, 2021).

Data hasil pengukuran kualitas air selanjutnya dianalisis untuk menentukan status mutu kualitas air sungai menggunakan pendekatan Indeks Pencemaran (IP) kemudian dibandingkan dengan baku mutu kelas 2. Berdasarkan Peraturan Menteri Lingkungan Hidup No. 115 Tahun 2003, Indeks Pencemaran menggunakan rumus :

$$
\begin{aligned}
& I P j=\sqrt{\frac{\left(\frac{C t}{L t}\right)^{2} M+\left(\frac{C l}{L i j}\right)^{2} R}{2}} \\
& \text { Dimana : } \\
& \mathrm{IPj} \quad=\text { indeks pencemaran bagi peruntukan } \mathrm{j} \\
& \mathrm{Ci}=\text { konsentrasi paramater kualitas air } \mathrm{i} \\
& \text { Lij = konsentrasi parameter kualitas air i yang } \\
& \text { tercantum dalam baku peruntukkan air } \mathbf{j} \\
& \mathrm{M}=\text { Maksimum } \\
& \mathrm{R} \quad=\text { Rerata }
\end{aligned}
$$

Evaluasi terhadap nilai PI adalah :
a. $0 \leq \operatorname{PIj} \leq 1,0 \quad=$ memenuhi baku mutu (kondisi baik)
b. $1,0<\operatorname{PIj} \leq 5,0=$ cemar ringan
c. $5,0<\mathrm{PIj} \leq 10$ = cemar sedang
d. $\mathrm{PIj}>10=$ cemar berat

\section{HASIL DAN PEMBAHASAN}

\section{Kondisi Umum Sungai Subayang}

Sungai Subayang merupakan bagian dari Sub-sub Daerah Aliran Sungai (DAS) Subayang yang menjadi bagian dari Sub DAS Kampar Kiri Hulu yang bermuara ke Sungai Kampar Kiri (Syuhada et al., 2016). Sungai Subayang mengalir sepanjang $90 \mathrm{~km}$ dengan lebar kurang lebih 25 meter dengan kedalam 1-5 meter (Firdaus \& Elfis, 2017). 
Berdasarkan Badan Pusat Statistik (BPS) tahun 2020, kecamatan Kampar Kiri Hulu yang merupakan kecamatan hasil pemekaran Kecamatan Kampar Kiri ini terdiri atas 24 desa, terbagi menjadi 96 dusun, 192 RW dan 376 RT dengan mata pencaharian masyarakatnya yang beragam. Rata-rata masyarakat berprofesi sebagai petani, peternak dan pedagang. Dalam hal pengembangan bidang pertanian, komoditas sayuran setiap tahunnya mengalami penurunan, baik luas panen hingga jumlah produksinya, sementara komoditas perkebunan mengalami peningkatan, baik komoditas karet, kelapa hingga kelapa sawit. Untuk sektor ternak yang paling dominan ialah kerbau dengan jumlah mencapai 889 ekor. Untuk jenis usaha perdagangan, tercatat terdapat sebanyak 244 usaha perdagangan yang semuanya merupakan toko atau warung kelontong, sedangkan pasar hanya terdiri atas 3 pasar dan memiliki 1 Koperasi Unit Desa (KUD) yang berada di Gema.

\section{2) Tutupan Lahan Sub-sub DAS Subayang}

Luas wilayah Sub-sub DAS Subayang adalah 63.792 ha. Wilayah hilir kawasan ini berada di desa Tanjung Belit yang bermuara ke Sungai Kampar Kiri. Pada Gambar 1 diketahui bahwa tutupan lahan pada wilayah Sub-sub DAS Subayang terdiri atas hutan lahan kering primer, hutan lahan kering sekunder, pertanian lahan kering campuran, semak belukar dan lahan terbuka.

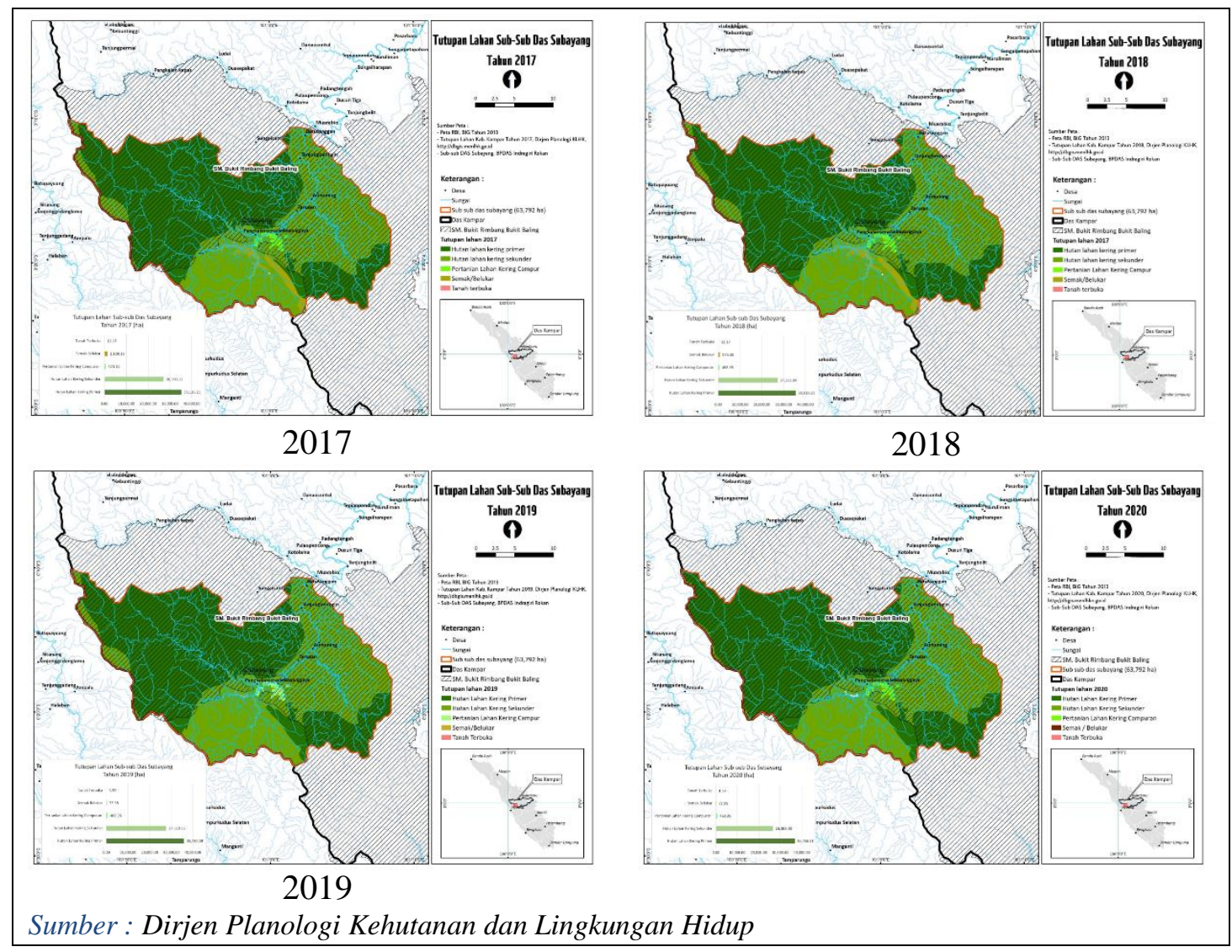

Gambar 1. Peta Tutupan Lahan Sub-sub DAS Subayang Tahun 2017-2020 
Berdasarkan peta rekapitulasi penutupan lahan dari Dirjen Planologi Kehutanan dan Lingkungan Hidup, persentase tiap jenis tutupan lahan tahun 2017-2020 dapat dilihat pada Tabel 1.

Tabel 1. Jenis dan Persentase Luas Tutupan Lahan Sub-sub DAS Subayang 2017- 2020

\begin{tabular}{lrrrr}
\hline \multirow{2}{*}{ Jenis Tutupan Lahan } & \multicolumn{4}{c}{ Luas Tutupan Lahan (\%) } \\
\cline { 2 - 5 } & 2017 & 2018 & 2019 & 2020 \\
\hline Hutan Lahan Kering Primer & 55,05 & 55,67 & 56,01 & 57,63 \\
Hutan Lahan Kering Sekunder & 42,31 & 42,67 & 43,14 & 41,51 \\
Pertanian Lahan Kering Campuran & 0,74 & 0,73 & 0,73 & 0,73 \\
Semak Belukar & 1,88 & 0,90 & 0,11 & 0,11 \\
Tanah Terbuka & 0,02 & 0,02 & 0,002 & 0,002 \\
\hline Jumlah & 100 & 100 & 100 & 100 \\
\hline
\end{tabular}

Tabel 1 menunjukkan bahwa luas tutupan lahan di wilayah Sub-sub DAS Subayang didominasi oleh jenis hutan lahan kering dengan hingga persentase luas area 97-99,15\%. Tren tutupan lahan pada tahun 2017-2020 tergolong stabil dan tidak menunjukkan perubahan signifikan. Untuk area hutan lahan kering primer justru terjadi peningkatan luasan sebesar $2.58 \%$ dari 2017 hingga 2020. Untuk luas tutupan lahan berupa hutan lahan kering sekunder, dari tahun 2017 hingga 2019 hanya terjadi peningkatan luas area sebesar 0,83\%, sedangkan pada tahun 2020 terjadi penurunan sebesar $1,63 \%$. Penurunan tersebut disebabkan oleh sebagian lahan hutan kering sekunder tersebut diinterpretasi sebagai hutan lahan kering primer pada tahun 2020.

Tutupan lahan selain hutan di Sub-sub DAS Subayang terdiri atas pertanian lahan kering campuran, semak belukar dan tanah terbuka (Tabel 1). Luas tutupan lahan untuk kelompok ini sangat kecil berkisar 0,85-3\%. Seperti halnya tutupan lahan jenis hutan, tutupan lahan jenis ini juga tidak mengalami perubahan signifikan. Untuk tutupan lahan jenis tanah terbuka cenderung stabil dan statis dan hanya mengalami sedikit penurunan sebesar $0,018 \%$ pada tahun 2019 . Sedangkan untuk luas area semak belukar, mengalami kecenderungan penurunan pada 2018 sebesar 0,98\%, dan $0,87 \%$ pada tahun 2019 kemudian statis di tahun 2020. Untuk tutupan lahan jenis pertanian lahan kering campuran terjadi penuruan $0,01 \%$ saja pada tahun 2018, sedangkan hingga 2020 luasnya tidak mengalami perubahan $(0,73 \%)$. Jenis tutupan lahan ini digunakan masyarakat untuk bertani. Minimnya luas lahan pertanian ini disebabkan kondisi lahan di wilayah ini yang berbukit sehingga cukup sulit dijadikan area bercocok tanam masyarakat. Kecenderungan minimnya luas area tutupan lahan selain hutan disebabkan oleh populasi penduduk yang tidak mengalami peningkatan pada periode waktu pengamatan (BPS, 2020). Dengan jumlah populasi yang tetap namun keperluan biaya hidup yang bertambah, masyarakat lebih memilih memanfaatkan lahan 
untuk kegiatan mata pencaharian dengan menanam tanaman yang dapat dipanen dan dijual serta memanfaatkan hasil hutan dan sungai untuk kebutuhan sehari-hari.

Meskipun luas tutupan lahan dari 2017 hingga 2020 tergolong stabil dan lestari, tidak menutup kemungkinan terjadinya kegiatan tidak bertanggung jawab yang dapat mengancam kelestarian hutan. Kegiatan seperti illegal logging sudah mulai terjadi tertuma di Desa Aur Kuning yang terletak di hulu dari Sub-sub DAS Subayang. Namun, peraturan adat setempat telah mengatur pola pemanfaatan dan penggunaan hutan dan hasil hutan tersebut. Peraturan adat dan kearifan lokal masyarakat Subayang itu juga dinyatakan dalam prosiding pengelolaan DAS terpadu (Firdaus \& Elfis, 2017).

Berdasarkan hasil wawancara dengan masyarakat, sepanjang tahun 2017-2020 tidak terjadi kebakaran pada wilayah Sub-sub DAS Subayang yang menyebabkan terjadinya perubahan tutupan lahan. Pernyataan masyarakat ini juga didukung melalui hasil pemantauan titik panas SNPP LAPAN Sipongi pada tahun 2017-2020, bahwa tidak ditemukan adanya titik panas yang terpantau di wilayah ini, sehingga tidak ada perubahan pola tutupan lahan dari tutupan lahan hutan menjadi areal terbuka.

\section{Aktivitas Masyarakat di sekitar Sungai Subayang}

Berdasarkan hasil wawancara yang dilakukan terhadap 46 responden di 3 desa didapatkan data pekerjaan masyarakat seperti pada Tabel 2.

Tabel 2. Persentase Jenis Pekerjaan Masyarakat di bantaran Sub-sub DAS Subayang

\begin{tabular}{cccccccc}
\hline & \multicolumn{6}{c}{ Persentase Jenis Pekerjaan Masyarakat (\%) } \\
\cline { 2 - 8 } Nama Desa & $\begin{array}{c}\text { Petani } \\
\text { Sawit }\end{array}$ & $\begin{array}{c}\text { Petani } \\
\text { Sawit } \\
\text { dan } \\
\text { Karet }\end{array}$ & $\begin{array}{c}\text { Petani Sawit } \\
\text { disertai } \\
\text { pekerjaan } \\
\text { lainnya }\end{array}$ & $\begin{array}{c}\text { Petani } \\
\text { Karet }\end{array}$ & $\begin{array}{c}\text { Petani } \\
\text { Karet } \\
\text { disertai } \\
\text { pekerjaan } \\
\text { lain }\end{array}$ & $\begin{array}{c}\text { Lain } \\
\text { nya }\end{array}$ & Total \\
\hline Aur Kuning & 0 & 0 & 0 & 59 & 18 & 23 & 100 \\
Batu Songgan & 0 & 0 & 0 & 40 & 30 & 30 & 100 \\
Tanjung Belit & 25 & 10 & 30 & 15 & 0 & 20 & 100 \\
\hline
\end{tabular}

Desa Aur Kuning berada di wilayah hulu Sungai Subayang dengan luasan wilayah 4.600 ha dengan total penduduk sebanyak 705 jiwa (BPS, 2020). Pada Tabel 2 terlihat bahwa, sebagian besar masyarakat Desa Aur Kuning bekerja sebagai petani karet (59\%), 18\% dari responden selain bertani karet juga memiliki pekerjaan lain seperti nelayan, dan 24\% sisanya memiliki mata pencaharian lain seperti membuka warung kelontong, berjualan di pasar apung dan pegawai di kantor desa. Sementara pekerjaan masyarakat di desa Batu Sanggan dengan jumlah penduduk 450 jiwa (BPS, 2020), tidak berbeda dengan masyarakat di Desa Aur Kuning. Sebesar $40 \%$ responden memiliki 
mata pencaharian sebagai petani getah karet, $30 \%$ lainnya selain bertani karet juga bekerja sebagai nelayan. Ada 30\% responden lainnya memiliki pekerjaan utama yang beragam, seperti menjadi pegawai di kantor desa, menjadi pedagang toko kelontong dan ada juga yang masih pengangguran. Sementara di desa Tanjung Belit sebagian besar warga memiliki mata pencaharian utama sebagai petani sawit (25\%). Desa yang menjadi daerah hilir dari penelitian ini memiliki jumlah penduduk 813 jiwa (BPS, 2020) dengan 15\% responden bermata pencaharian sebagai petani karet. Persentase responden yang merupakan petani karet dan petani sawit sebesar 10\% sedangkan 20\% lainnya tanpa pekerjaan tetap. Sebanyak 30\% dari responden di desa ini memiliki pekerjaan sebagai petani sawit dan juga diiringi dengan pekerjaan lain seperti nelayan, membuka toko kelontong, penjual pulsa dan aparatur desa.

Berdasarkan hasil wawancara, masyarakat bekerja sebagai petani karet karena tidak memerlukan modal yang besar. Pohon karet di perkebunan berasal dari kebun nenek moyang yang sudah diwariskan turun-temurun. Penjualan getah dilakukan di Pasar Gema dengan transportasi menggunakan piyau untuk mengarungi Sungai Subayang. Meskipun demikian, penghasilan yang diterima para petani tidak menjanjikan, hasil yang didapat tergantung pada musim. Apabila musim hujan, maka warga tidak mendapat hasil panen. Untuk dapat mencukupi kebutuhan hidup, maka masyarakat menangkap ikan di sungai dan mengumpulkan buah-buahan yang tumbuh di hutan untuk dimakan sehari-hari serta mengandalkan bantuan tunai yang diberikan pemerintah daerah. Sementara masyarakat di desa Tanjung Belit menjadi petani kelapa sawit dikarenakan masa panen kelapa sawit lebih singkat dibanding panen getah karet, sehingga masyarakat lebih cepat memperoleh keuntungan dari hasil panen. Pasar untuk kelapa sawit juga lebih banyak dan lebih mudah ditemui dibandingkan pasar getah karet. Tanaman kelapa sawit masyarakat ditanam dengan pola sisipan di antara pepohonan yang sudah ada sehingga tidak memerlukan pembukaan lahan.

Untuk aktivitas rumah tangga seperti mandi, cuci dan kakus (MCK) serta pengelolaan sampah hasil rumah tangga berdasarkan observasi dan wawancara didapatkan hasil seperti pada Gambar 2 dan Tabel 3. 


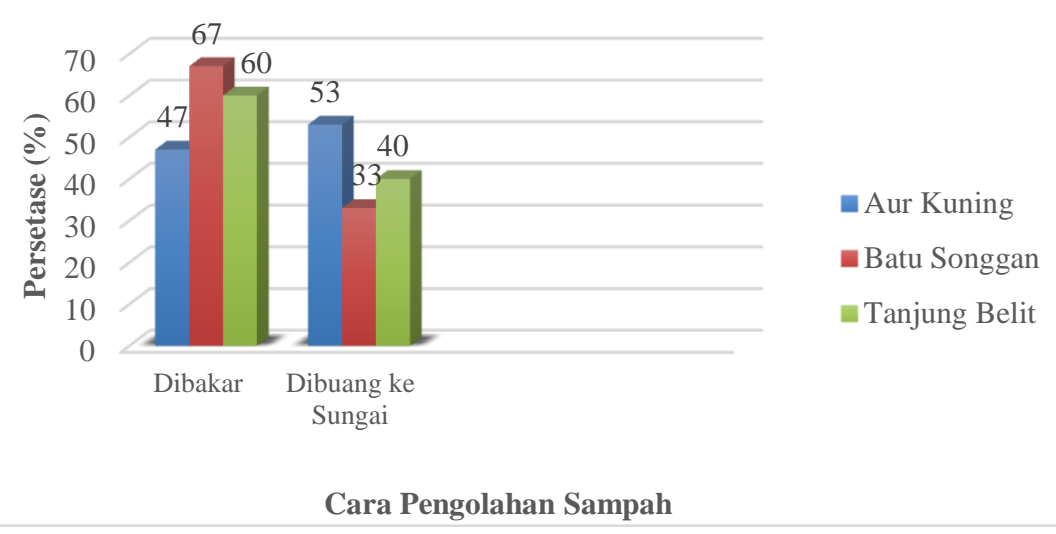

Gambar 2. Persentase Pengolahan Sampah Rumah Tangga di sekitar Sub-sub DAS Subayang

Pada Gambar 2 terlihat bahwa pengolahan sampah pada masyarakat yang tinggal di bantaran Sungai Subayang dilakukan dengan 2 jenis yaitu dibakar dan dibuang langsung ke sungai. Perbandingan kedua cara pengolahan sampah ini tidak berbeda jauh. Untuk di Desa Aur Kuning bahkan perbandingan masyarakat membuang sampah di sungai dan membakar adalah 47:53. Hal ini tidak jauh berbeda dengan di desa Tanjung Belit yaitu perbandingan persentase 60:40. Untuk desa Batu Songgan, warga sudah lebih peduli terhadap kebersihan sungai meski masih ditemukan kegiatan membuang sampah ke sungai (33\% responden).

Membuang sampah langsung ke sungai tentu akan mencemari kualitas perairan sungai. Hal ini tentu akan memberi efek negatif kembali kepada masyarakat sekitar karena sungai adalah sumber air untuk kebutuhan sehari-hari. Warga biasanya menumpuk sampah dan membiarkan hingga busuk sebelum dibakar guna menghemat bahan bakar untuk membakar sampah. Kebiasaan ini menimbulkan masalah lingkungan seperti peningkatan $\mathrm{pH}$ tanah. Selain itu, asap hasil pembakaran melepaskan banyak polutan beracun seperti karbon monoksida, formaldehida, arsenik, dioksin dan furan. Menurut Rahman dalam Tamin (2021), polutan hasil pembakaran tersebut jika terhirup oleh menimbulkan berbagai penyakit seperti batuk, serangan asma, ruam, mual, sakit kepala, dan efek jangka panjangnya menimbulkan gangguan sistem kekebalan tubuh hingga menimbulkan jenis kanker tertentu. Pembakaran juga berdampak pada pengrusakan ozon dan meningkatkan suhu lingkungan. Kebiasaan pengolahan sampah yang masih belum baik tersebut terjadi karena ketidak tahuan masyarakat. Lebih lanjut, masyarakat mengatakan tidak ada edukasi dari pemerintah ataupun inisiatif dari pemuda desa untuk mengelola sampah lebih efektif dan ramah lingkungan.

Kegiatan masyarakat terkait mandi, mencuci dan kakus (MCK), banyak diantaranya sudah tidak lagi dilakukan di Sungai Subayang. Seperti terlihat pada Tabel 3, sebagian besar masyarakat sudah melakukannya di rumah masing-masing karena sudah memiliki kamar mandi sendiri yang 
disertai jamban. Selain itu, adanya pembangunan toilet umum yang dibangun tahun 2017 lebih membantu masyarakat yang tidak mempunyai kamar mandi dan jamban pribadi di rumah untuk melakukan aktivitas MCK di toilet umum. Khusus untuk di desa Tanjung Belit, terdapat lebih banyak toilet umum yang diperuntukkan untuk pengunjung yang melakukan ekowisata air terjun di Desa Tanjung Belit.

Tabel 3. Persentase Aktivitas MCK Warga di sekitar Sub-sub DAS Subayang

\begin{tabular}{|c|c|c|c|c|c|}
\hline \multirow[t]{2}{*}{ Desa Pengamatan } & \multicolumn{2}{|c|}{$\begin{array}{c}\text { Persentase Lokasi } \\
\text { Aktivitas } \\
\text { Mandi dan Cuci Warga } \\
(\%)\end{array}$} & \multicolumn{3}{|c|}{$\begin{array}{c}\text { Persentase Lokasi Aktivitas } \\
\text { Kakus Warga (\%) }\end{array}$} \\
\hline & Rumah & Sungai & Rumah & Sungai & $\begin{array}{l}\text { Toilet } \\
\text { Umum }\end{array}$ \\
\hline Aur Kuning & 76 & 24 & 35 & 29 & 35 \\
\hline Batu Songgan & 100 & 0 & 67 & 0 & 33 \\
\hline Tanjung Belit & 100 & 0 & 100 & 0 & 0 \\
\hline
\end{tabular}

Seperti halnya kebiasaan masyarakat di hulu sungai, pada Tabel 3 terlihat bahwa masyarakat Aur Kuning masih ada yang melakukan aktivitas mandi dan cuci (24\%) dan kakus (29\%) di sungai. Hal ini dikarenakan belum semua rumah memiliki kamar mandi dan jamban. Sementara warga di Desa Batu Sanggan dan Desa Tanjung Belit desa lainnya, meskipun responden sudah tidak melakukan aktivitas MCK di sungai namun berdasarkan wawancara, beberapa waktu masyarakat masih melakukan mandi dan cuci di sungai. Hal ini dilakukan dengan anggapan dapat memperkuat keakraban antar warga melalui komunikasi selama melakukan aktivitas mandi dan mencuci tersebut.

Kondisi lingkungan di area Sungai Subayang masih tergolong alami dan terjaga, hal ini menjadi daya tarik wisatawan. Pada Gambar 3 terlihat, bahwa Desa Batu Songgan dan Desa Tanjung Belit masuk ke dalam desa dengan daya tarik wisata di kawasan Bukit Rimbang-Baling. Desa Tanjung Belit merupakan pintu masuk utama menuju area wisata di desa lainnya. Di wilayah ini terdapat beberapa spot air terjun dan camping area. Selain itu mulai beroperasinya laboratorium air tawar Subayang oleh WWF Indonesia pada 2017 juga menjadi bagian dari wisata edukasi. 


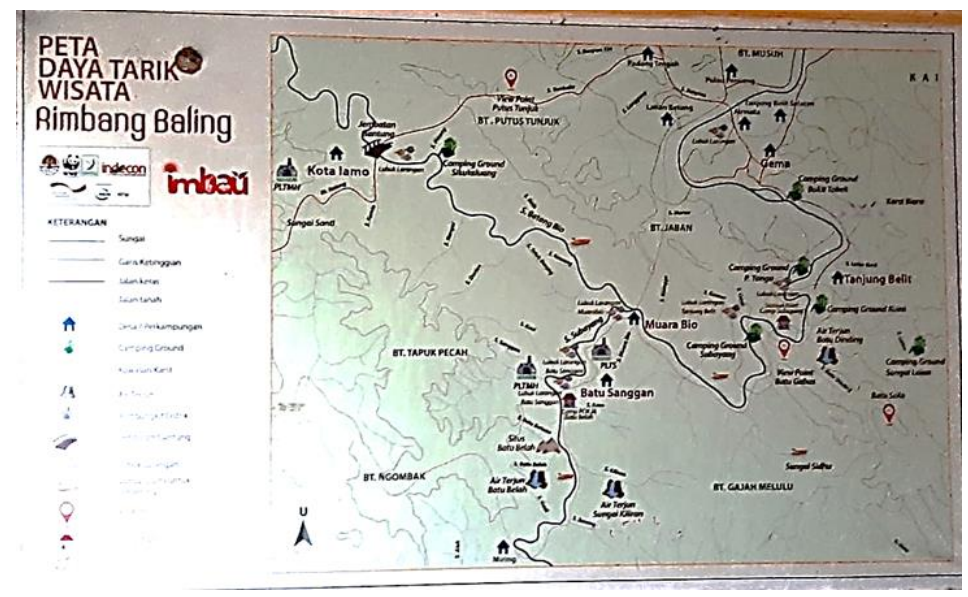

Gambar 3. Peta Daya Tarik Wisata Bukit Rimbang Bukit Baling (Sumber : WWF Indonesia-Central Sumatra)

Berdasarkan wawancara dengan aparat desa dan niniek mamak, tidak banyak masyarakat luar daerah Kecamatan Kampar Kiri Hulu yang datang ke Desa Aur Kuning. Masyarakat berkunjung biasanya hanya mahasiswa yang melakukan penelitian dan pemerintah setempat yang melakukan pengecekan atau pemberian bantuan sosial. Berbeda dengan Desa Aur Kuning, sejak 2020 masyarakat Desa Batu Songgan sudah mulai menerima mahasiswa untuk kegiatan Kuliah Kerja Nyata $(\mathrm{KKN})$. Walaupun menerima mahasiswa luar untuk menginap, aktivitas pengunjung tersebut tetap dikontrol, baik MCK hingga pengelolaan sampah masih sama seperti yang dilakukan masyarakat Desa Batu Songgan. Bahkan dengan kehadiran mahasiswa juga menghimbau masyarakat untuk tidak membuang sampah di sungai. Sementara itu, Desa Tanjung Belit sangat sering dikunjungi oleh warga di luar kecamatan kampar-kiri Hulu sehingga berdampak pada banyaknya aktivitas di Desa Tanjung Belit yang dapat meningkatkan resiko pencemaran terhadap sungai.

\section{Kualitas Perairan Subayang 2017-2020}

Indikator yang dianalisis dalam penentuan kualitas air Sub-sub DAS Subayang meliputi: suhu air, nilai kekeruhan, kecepatan aliran air, nilai oksigen terlarut dan derajat keasaman air $(\mathrm{pH})$. Data-data untuk indikator tersebut bersumber dari hasil pengukuran kualitas air dengan nilai rata tahunan yang telah dilakukan oleh Tim Fresh Water and Fisheries WWF Indonesia-Central Sumatra. 


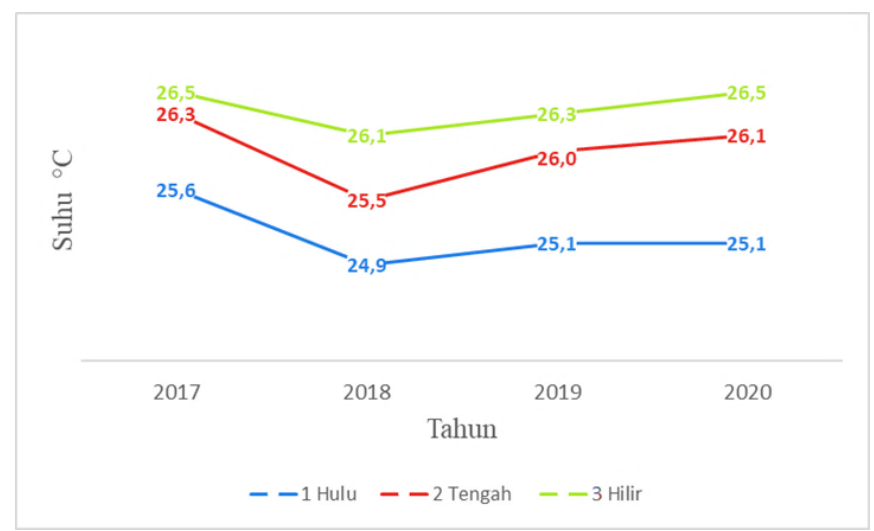

Gambar 4. Grafik Suhu Perairan Sungai Subayang 2017-2020

Pada Gambar 4, terlihat bahwa dari 2017 - 2020 nilai rata-rata suhu berada pada $24,9^{0} \mathrm{C}$ $26,5^{\circ} \mathrm{C}$. Perbedaan suhu antar 3 lokasi sampel tidak menunjukan perbedaan yang signifikan. Data pengukuran tersebut menujukkan bahwa suhu perairan Subayang tergolong baik karena nilai tersebut tidak melebihi baku mutu air sungai kelas ke 2 yaitu deviasi 3 dari suhu alamiahnya yaitu $25^{\circ} \mathrm{C}$ (Peraturan Pemerintah No. 22 Tahun 2021). Kisaran suhu tersebut memungkinkan plankton dan ikan tumbuh dan berkembang karena plankton pada daerah tropis berada di kisaran suhu 20$30^{\circ} \mathrm{C}$ (Agustini et al., 2014).

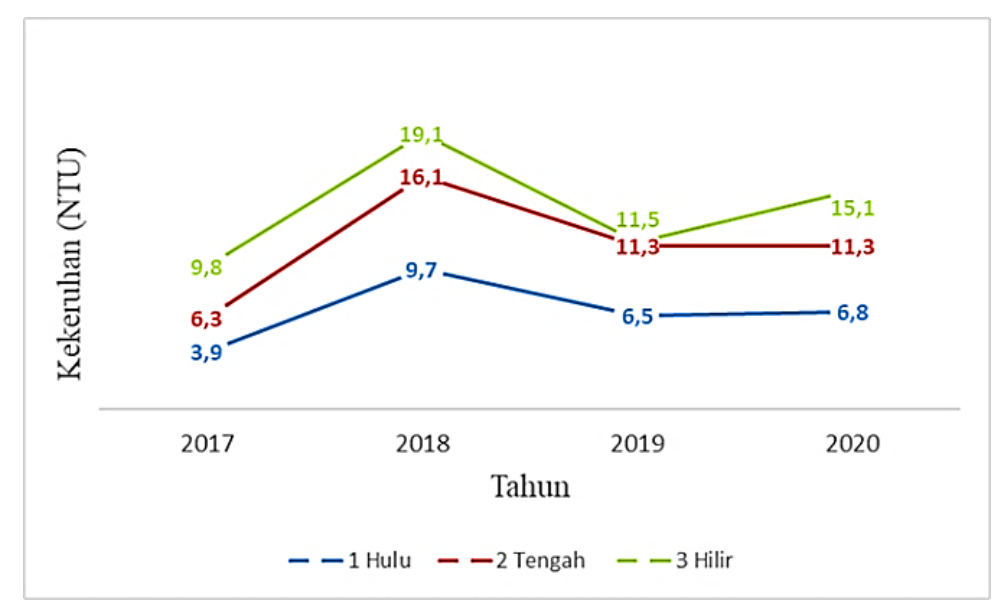

Gambar 5. Grafik Nilai Kekeruhan Sungai Subayang Tahun 2017-2020

Kekeruhan memiliki nilai penting dalam parameter pengukuran kualitas air karena mempengaruhi penetrasi cahaya ke dalam air yang mengakibatkan terhalangnya fotosintesis oleh organisme fitoplankton seperti alga dan vegetasi lainnya yang menempel dan terendam dalam air (Agustini et al., 2014). Berdasarkan pengukuran nilai kekeruhan dapat disajikan data rerata nilai kekeruhan sungai Subayang seperti pada Gambar 5.

Berdasarkan NTAC (1968) nilai ambang batas kekeruhan perairan adalah 25 NTU. Berdasarkan Gambar 5, terlihat bahwa nilai kekeruhan berkisar 3,9-19,1 NTU. Hal ini mengindikasikan bahwa perairan Subayang masih baik. Fitoplankton butuh cahaya yang cukup 
untuk berfotosintesis (Kasry et al., 2012), dengan nilai kekeruhan yang di bawah baku mutu memungkinkan cahaya masuk ke permukaan air sungai sehingga dapat dipergunakan fitoplankton untuk berfotosintesis. Keberadaan fitoplankton merupakan awal baik pembentukan suatu jaring makanan yang sehat di perairan.

Data parameter kecepatan aliran arus sungai dari hulu ke hilir selama 2017-2020 dapat dilihat pada Gambar 6.

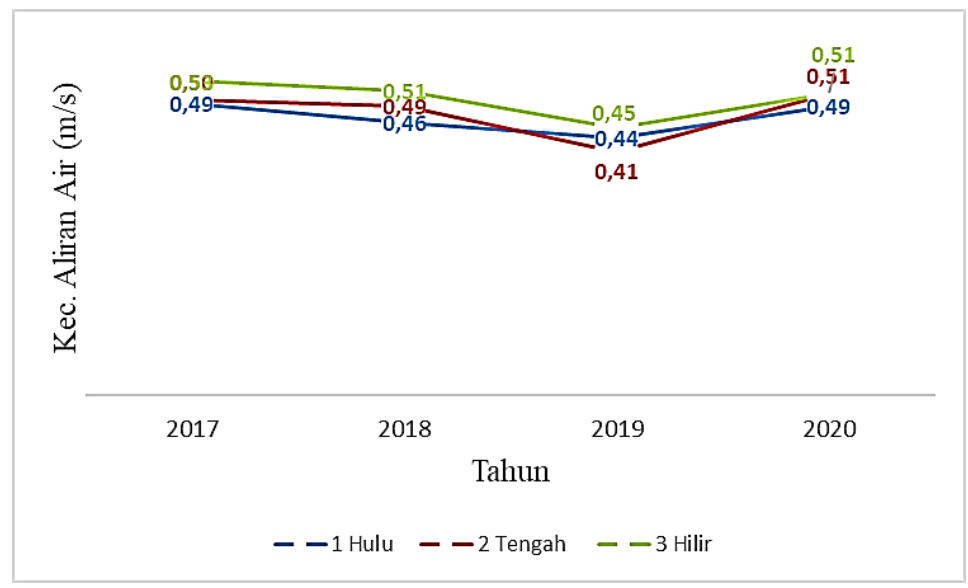

Gambar 6. Grafik Pengukuran Kecepatan Aliran Air Sungai Subayang 2017-2020

Berdasarkan Gambar 6, diketahui bahwa aliran air dari hulu ke hilir sangat lancar karena tidak terjadi perbedaan signifikan dari tahun ke tahun. Pada tahun2017 arus hulu ke hilir hanya berbeda kecepatan $0,01 \mathrm{~m} / \mathrm{s}$. Sedangkan pada tahun 2018 arus semakin ke hilir semakin deras. Untuk tahun 2019, terdapat penurunan kecepatan arus di bagian tengah dibandingkan bagian hulu dan hilir. Sedangkan pada tahun 2020, kecepatan arus kembali menunjukkan pergerakkan yang sama dengan tahun 2017 dan 2018.

Secara keseluruhan, kecepatan aliran air pada penelitian ini berada pada kisaran 0,39-0,51 m/s. Angka tersebut menunjukkan bahwa perairan Sungai Subayang memiliki kategori arus sedang. Pembagian kategori kecepatan arus berdasarkan kategori Mason (1993) yaitu perairan yang mempunyai arus $>1 \mathrm{~m} / \mathrm{s}$ dikategorikan sebagai arus sangat deras, perairan dengan arus $>0,5-1 \mathrm{~m} / \mathrm{s}$ dikategorikan sebagai arus deras, kecepatan arus 0,25-0,5 m/s dikategorikan arus sedang, kecepatan arus $0,1-0,25 \mathrm{~m} / \mathrm{s}$ di kategorikan arus lambat dan kecepatan arus $<0,1 \mathrm{~m} / \mathrm{s}$ dikategori arus sangat lambat.

Aerasi pada permukaan merupakan sumber oksigen utama perairan. Dissolved oxygen (DO) atau kandungan oksigen terlarut dalam suatu perairan merupakan faktor yang sangat penting dalam ekosistem perairan, terutama untuk proses respirasi bagi organisme air (Effendi, 2003). Berdasarkan PP Nomor 22 Tahun 2021, kandungan oksigen terlarut yang baik dan dapat mendukung kehidupan ikan dengan layak adalah tidak kurang dari $4 \mathrm{mg} / \mathrm{l}$. 


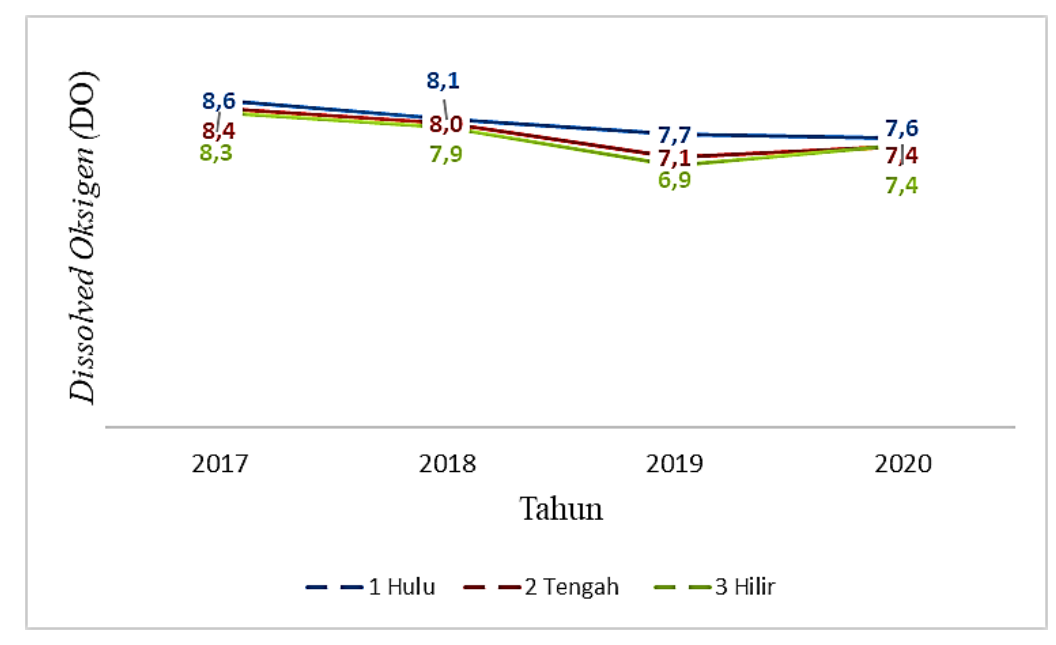

Gambar 7. Grafik Dissolved Oxygen (DO) Sungai Subayang 2017-2020

Berdasarkan Gambar 7, nilai DO di Sungai Subayang selalu melebihi nilai minimum DO yaitu berada pada nilai $6,9-8,7 \mathrm{mg} / \mathrm{l}$. Hal ini menandakan bahwa Sungai Subayang memenuhi kriteria yang baik bagi kehidupan organisme air baik jenis ikan-ikan, plankton dan juga bentos. Sugianti dan Lismining (2018) menjelaskan bahwa oksigen terlarut di dalam perairan dibutuhkan organisme-organisme perairan untuk respirasi.

Meskipun dari 2017-2020 nilai DO Sungai Subayang tergolong baik, namun dari tahun ke tahun terjadi penurunan nilai DO. Pada tahun 2017 di wilayah hulu, tercatat nilai DO senilai 8,6 $\mathrm{mg} / \mathrm{l}$, sedangkan pada 2018 terjadi penurunan senilai $0,5 \mathrm{mg} / \mathrm{l}$ menjadi $8,1 \mathrm{mg} / \mathrm{l}$, dan pada 2019 turun menjadi 7,7 mg/l (turun $0,4 \mathrm{mg} / \mathrm{l}$ ) serta $7,6 \mathrm{mg} / \mathrm{l}$ pada 2020 (turun $0,1 \mathrm{mg} / \mathrm{l}$ ). Sementara di wilayah tengah hinga 2017 hingga 2019 terjadi penurunan hingga 0,7 mg/l dan wilayah hilir bahkan turun hingga 1,4 mg/l meskipun pada tahun 2020 nilai kedua area ini kembali naik hingga 0,3 mg/l di wilayah tengah dan $0,5 \mathrm{mg} / \mathrm{l}$ di wilayah hilir.

Power of Hydrogen atau $\mathrm{pH}$ adalah parameter yang dapat mempengaruhi keseimbangan senyawa-senyawa yang terdapat di dalam perairan serta mempengaruhi fisiologi ikan. Nilai $\mathrm{pH}$ yang ideal bagi pemeliharaan ikan ialah berada pada kisaran 6,5-8,5 pH (NTAC, 1968 ; NASNAE, 1972), dan organisme akuatik (makroinvertebrata) menyukai kondisi air dengan pH 7-8,5 ((Effendi, 2003)). 


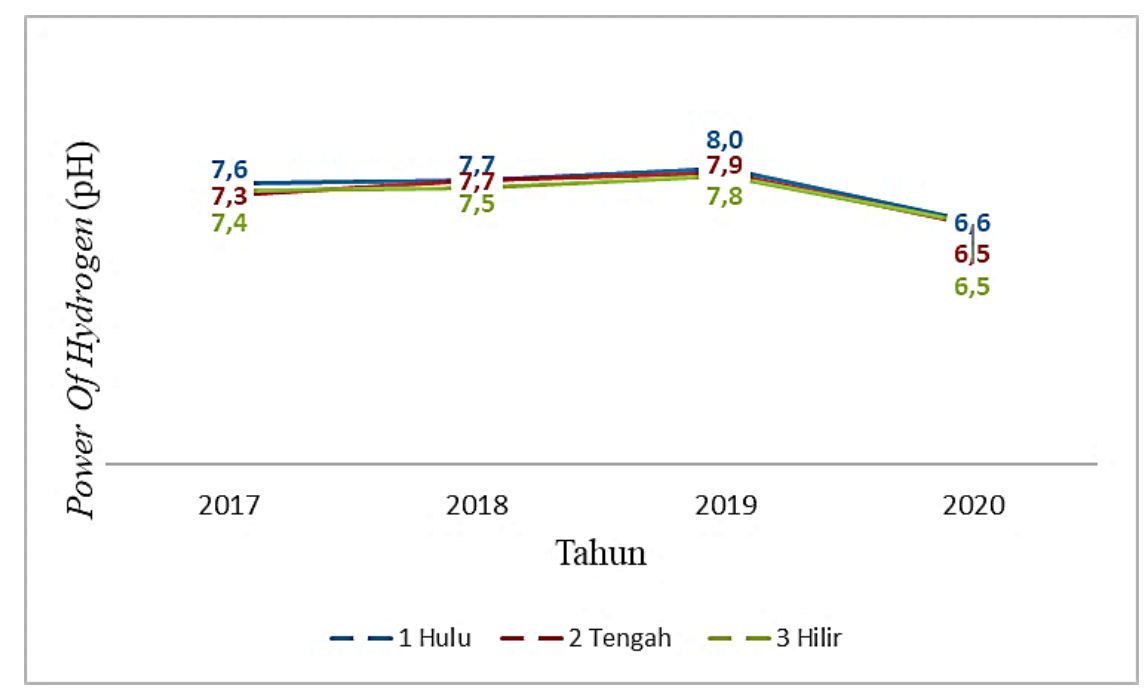

Gambar 8. Grafik Pengukuran pH Sungai Subayang Tahun 2017-2020

Data pengukuran nilai $\mathrm{pH}$ rata-rata tahunan di Sungai Subayang terlihat pada Gambar 8 Nilai pH sungai baik di hulu hingga ke hilir selama 4 tahun berada pada kisaran 6,5-8. Nilai tersebut tergolong baik karena masih di batas ambang nilai baku mutu yaitu 6-9 (PP Nomor 22 Tahun 2021). Kisaran nilai tersebut mencukupi angka kelayakan hidup bagi plankton dan ikan-ikan karena $\mathrm{pH}$ berkaitan dengan dengan ketersediaan fosfat, nitrogen dan nutrien lain sebagai bahan pangan untuk pertumbuhan plankton dan ikan-ikan air tawar lainnya (Agustini et al., 2014).

Terlihat pada Gambar 8, nilai pH wilayah hilir cenderung lebih rendah dari pada wilayah lainnya, meskipun perbedaannya tidak signifikan. Hal tersebut disebabkan karena limbah organik dari hulu dan tengah akan menumpuk di bagian hilir. Sementara secara rata-rata pertahun, kadar $\mathrm{pH}$ pada tahun 2019 memiliki cenderung lebih rendah di setiap wilayah pengamatan dibanding tahun sebelumnya, dan tahun 2020 cenderung lebih tinggi dibanding 3 tahun sebelumnya.

\section{Kaitan Tutupan Lahan dan Aktivitas Masyarakat dengan Kualitas Air Sungai Subayang}

Keberadaan tutupan lahan berupa hutan yang masih mendominasi ini sangat berpengaruh terhadap terjaganya kualitas perairan Sungai Subayang. Asdak, (2007) menyebutkan bahwa tutupan lahan mempengaruhi besar kecilnya evapotranspirasi, infiltrasi, perkolasi, air larian, air permukaan, kandungan air tanah, aliran sungai, kekeruhan air, suhu air, hingga erosi yang terjadi di sekitar sungai. Tutupan lahan yang baik untuk pengelolaan DAS adalah tutupan lahan berupa hutan. Pada Tabel 4, secara rerata dari hulu ke hilir terlihat bahwa kualitas perairan Sungai Subayang masih dalam kategori baik dan sesuai dengan baku mutu air. 
Tabel 4. Rerata Hasil Pengukuran Parameter Kimia-Fisika Sungai Subayang 2017- 2020

\begin{tabular}{|c|c|c|c|c|c|c|}
\hline Tren & Parameter & $\begin{array}{c}\text { Nilai Baku } \\
\text { Mutu }\end{array}$ & 2017 & 2018 & 2019 & 2020 \\
\hline 1 & Suhu & $25{ }^{\circ} \mathrm{C}(+/-3)$ & $26,1 \quad{ }^{\circ} \mathrm{C}$ & $25,5 \quad{ }^{\circ} \mathrm{C}$ & $25,8 \quad{ }^{\circ} \mathrm{C}$ & $25,9 \quad{ }^{\circ} \mathrm{C}$ \\
\hline 2 & Kekeruhan & $\begin{array}{c}\text { Maks. } 25 \\
\text { NTU }\end{array}$ & 6,7 NTU & $15,0 \mathrm{NTU}$ & 9,8 NTU & $11,1 \mathrm{NTU}$ \\
\hline 3 & $\begin{array}{l}\text { Kecepatan } \\
\text { Arus }\end{array}$ & $>25 \mathrm{~m} / \mathrm{s}$ & $0,5 \mathrm{~m} / \mathrm{s}$ & $0,5 \mathrm{~m} / \mathrm{s}$ & $0,4 \mathrm{~m} / \mathrm{s}$ & $0,5 \mathrm{~m} / \mathrm{s}$ \\
\hline 4 & $\begin{array}{l}\text { Oksigen } \\
\text { Terlarut }\end{array}$ & $>4 \mathrm{mg} / \mathrm{l}$ & $8,4 \mathrm{mg} / \mathrm{l}$ & $8,0 \mathrm{mg} / \mathrm{l}$ & $7,2 \mathrm{mg} / \mathrm{l}$ & $7,5 \mathrm{mg} / \mathrm{l}$ \\
\hline 5 & $\mathrm{pH}$ & $6-9$ & 7,4 & 7,6 & 7,9 & 6,5 \\
\hline
\end{tabular}

Hubungan antara tutupan lahan dan aktivitas masyarakat dengan kualitas air dilihat melalui analisis status mutu air dengan pendekatan indeks pencemaran (IP) untuk menunjukkan tingkat pencemaran suatu sumber air yang kemudian dibandingkan dengan status baku mutu air tersebut. Hasil analisis status mutu air Sungai Subayang disajikan pada Tabel 5.

Tabel 5. Hasil Analisis Indeks Pencemaran di Sungai Subayang 2017-2020

\begin{tabular}{|c|c|c|c|c|c|c|}
\hline \multirow{2}{*}{ No } & \multirow{2}{*}{ Lokasi Pengamatan } & \multicolumn{4}{|c|}{ Indeks Pencemaran } & \multirow{2}{*}{ Rerata } \\
\hline & & 2017 & 2018 & 2019 & 2020 & \\
\hline 1 & Desa Aur Kuning & 0,27 & 0,30 & 0,31 & 0,30 & 0,30 \\
\hline 2 & Desa Batu Sanggan & 0,58 & 0,49 & 0,40 & 0,67 & 0,54 \\
\hline 3 & Desa Tanjung Belit & 0,75 & 0,80 & 0,80 & 0,80 & 0,79 \\
\hline & Rerata & $\mathbf{0 , 5 3}$ & $\mathbf{0 , 5 3}$ & 0,50 & 0,59 & 0,55 \\
\hline
\end{tabular}

Tabel 5 menunjukkan bahwa kondisi status mutu air Sungai Subayang yang berada pada kondisi baik di seluruh wilayah pengamatan setiap tahun $(0 \leq \operatorname{PIj} \leq 1,0)$. Status mutu air Sungai Subayang yang berada pada level baik ini tidak terlepas dari perilaku masyarakat dalam kegiatan sehari-hari dan perilaku masyarakat dalam melestarikan hutan. Parameter-parameter kualitas air baik fisika, kimia dan biologi disebabkan oleh aktivitas masyarakat dan kondisi tutupan lahan yang saling berkaitan satu sama lainnya.

Kebiasan membuang sampah dan MCK di sungai, mengelola sampah dengan cara dibakar, kegiatan produksi getah karet yang menghasilkan limbah, nyatanya beresiko terhadap pencemaran air sungai. Namun, tutupan lahan dengan jenis hutan yang masih tinggi dapat mengurangi dampak tersebut. Moon et al. (2001), Amiri et al. (2006) dan Noktavia et al. (2019) dalam penelitiannya juga menyatakan bahwa keberadaan hutan dengan vegetasi pepohonannya dapat mengurangi resiko pencemaran air sungai.

Keberadaan hutan yang masih lestari ini tidak terlepas dari kearifan lokal masyarakat Subayang. Masyarakat dilarang menebang hutan dan menangkap ikan secara berlebihan, terutama 
di wilayah lubuk larangan. Perilaku dan aktivitas masyarakat yang arif inilah menyebabkan kondisi air Sungai Subayang berada pada kondisi yang baik dan dapat dimanfaatkan oleh masyarakat untuk kebutuhan sehari-hari. Hal ini sejalan dengan Syuhada (2016) yang menyatakan bahwa kondisi kualitas air Sungai Subayang pada tahun penelitian tersebut juga berada pada kondisi baik. (Perdana, 2017) menyebutkan kearifan lokal masyarakat dalam menjaga alam dan dalam aktivitas masyarakatnya menjadikan kondisi mutu air masih terjaga level mutunya pada kondisi baik.

\section{KESIMPULAN}

Berdasarkan analisis data yang telah dilakukan, dapat disimpulkan bahwa tutupanan lahan di Sub-sub DAS Subayang hingga 2020 didominasi hutan lahan kering (99,14\%). Perekomian masyarakat di sekitar Sungai Subayang ditopang oleh hasil hutan serta pertanian karet dan kelapa sawit. Geliat wisata alam mulai meningkat di desa Batu Songgan dan Desa Tanjung Belit. Kegiatan MCK di sungai menunjukkan trend penurunan sementara pengelolaan sampah masih dilakukan dengan cara dibakar dan dibuang ke sungai. Keberadaan tutupan lahan berupa hutan dan aktivitas masyarakat yang memiliki kearifan lokal berpengaruh terhadap kualitas perairan Sungai Subayang yang berada pada kualitas baik dengan dengan Indeks Pencemaran (IP) berkisar 0,27-0,80 sehingga memenuhi nilai standart baku mutu kelas 2 (kondisi baik).

Kedepannya, perlu adanya penelitian lebih lanjut dalam penentuan kualitas air Sungai Subayang berdasarkan parameter yang lebih detil untuk pemenuhan peruntukan air baku air minum. Melihat aktivitas pengolahan limbah masyarakat yang masih mencemari lingkungan maka dibutuhkan sosialisasi kepada masyarakat tentang cara mengelola sampah yang ramah lingkungan oleh pemerintah maupun akademisi dan aktivis lingkungan. Meskipun kondisi tutupan hutan yang masih asri, tetap perlu adanya upaya preventif dan persuasif oleh pemerintah dan pemuka adat dalam mengantisipasi maraknya kasus illegal logging di bagian hulu Sungai Subayang.

\section{UCAPAN TERIMA KASIH}

Penulis mengucapkan terima kasih banyak kepada WWF Indonesia-Central Sumatra yang telah menyediakan data, sarana dan prasarana dalam menunjang penelitian ini serta Dirjen Planologi Kehutanan dan Balai Besar Konservasi Sumber Daya Alam Riau atas bantuan data dan perizinan yang diberikan. 


\section{DAFTAR PUSTAKA}

Agustini, M., Oetami, S., Universitas, M., \& Surabaya, S. (2014). Identifikasi Dan Kelimpahan Plankton Pada Budidaya Ikan Air Tawar Ramah Lingkungan. Jurnal Agroknow, 2(1): 39-43

Amalia, B.I dan Sugiri, A. (2014). Ketersediaan air bersih dan perubahan iklim: Studi krisis air di Kedungkarang Kabupaten Demak. Teknik Perencanaan Wilayah Kota 3(2): 295-302.

Amiri., Bahman, J dan Kaneyuki, N. (2006). Modeling the Relationship between Land and River Water Quality in the Yamaguchi Prefecture of Japan. Field Biol Journal 29 (4) : 343-352.

Asdak, C. (2007). Hidrologi dan Pengelolaan Daerah Aliran Sungai. Yogyakarta. Gadjah Mada University Press.

Badan Pusat Statistik Kabupaten Kampar. (2020). Kecamatan Kampar Kiri Hulu Dalam Angka 2020. Kampar. BPS Kab. Kampar.

Badan Standardisasi Nasional. (2004). Tata Cara Pengambilan Contoh Dalam Rangka Pemantauan Kualitas Air Pada Suatu Daerah Pengaliran Sungai. Jakarta.

Effendi, H. (2003). Telaah Kualitas Air Bagi Pengelolaan Sumberdaya Dan Lingkungan Perairan. . Kanisius.

Firdaus, L. N., \& Elfis, D. (2017). Prosiding Seminar Nasional Pengelolaan Daerah Aliran Sungai Secara Terpadu. (ONLINE) (http://mitrainsani.or.id/das-kampar diakses tanggal 20 Februari 2021)

Kalogirou, S. (2005). Seawater Desalination Using Renewable Energy Sources. Progress in Energy and Combustion Science, 31, 242-281.

Keputusan Menteri Lingkungan Hidup Nomor 115 Tahun 2003 tentang Pedoman Penentuan Status Mutu Air

Kasry, A., Nur, D., \& Fajri, E. (2012). Kualitas Perairan Muara Sungai Siak Ditinjau Dari Parameter Fisik-Kimia Dan Organisme Plankton. Jurnal Berkala Perikanan Terubuk 40(2): 96-113

Moon, Y.H., Jong, M.P., Jae, G.S dan Kea, H.K. (2001). Change in Water Quality on Upper Stream of Mankyeong River. Korean Journal of Environment Agriculture 20 (3): 252 - 257.

NASNAE. (1972). Ecological Research Series. Water Quality Criteria. Washington D.C. FWPCA

Noktavia, N., Suwarsito., \& Sarjanti, E. (2019). Pengaruh Penggunaan Lahan Terhadap Kualitas Air Sungai Pelus Di Sub Das Pelus Kabupaten Banyumas. Prosiding Seminar Nasional. Purwokerto.Universitas Muhammadiyah Purwokerto.

N.T.A.C. (1968). Water Quality Criteria. Washington D.C. FWPCA. 
Peraturan Dirjen Planologi Kehutanan Nomor P.1/VII-IPSDH/2015 Tahun 2015 tentang Pedoman Pemantauan Penutupan Lahan

Peraturan Menteri Lingkungan Hidup No 1 Tahun 2007 tentang Pedoman Pengkajian Teknis Untuk Menetapkan Kelas Air

Peraturan Pemerintah No. 22 Tahun 2021 tentang Penyelenggaraan, Perlindungan dan Pengelolaan Lingkungan HIdup.

Peraturan Pemerintah No 37 Tahun 2011 tentang Pengelolaan Daerah Aliran Sungai.

Peraturan Pemerintah No. 38 Tahun 2012 tentang Sungai

Perdana, R.F., Suwondo dan Darmadi (2017). Local Widom Management Lubuk Larangan In The Subayang River On The Development Of Environmental Education Courses Module. Pekanbaru. Universitas Riau

Pokja AMPL. (2005). Provinsi Riau Menuju Krisis Air Bersih Akut. (Online) http://www.ampl.or.id/digilib/read/provinsi-riau-menuju-krisis-air-bersih-akut/36127) diakses 27 Februari 2021 Pukul 12.00 WIB.

Sipongi Karhutla Monitoring System. Data Titik Panas SNPP (LAPAN). (Online) http://sipongi.menlhk.go.id/peta/?satelit=LPN-NPP\&dt\# diakses 17 September 2021 Pukul 23.00 WIB.

Susanto, D. (2021, July). Komunikasi pribadi tentang kualitas air Sungai Subayang.

Sugiyono.(2012). Memahami Penelitian Kualitatif. Bandung. Alfabeta.

Sugiyono.(2007). Metode Penelitian Kuantitatif Kualitatif dan R\&D. Bandung. Alfabeta.

Syuhada, N.I., Suwondo dan Fauziah, Y. (2016). Analysis Of Subayang River Quality Based On Biotilic Index As Enrichment Of Aquatic Ecology Module Biology Education Faculty Of Teacher Training And Education University Of Riau.

Tamin, R. (2021). Hati-hati, Membakar Sampah Bisa Membahayakan Kesehatan. (ONLINE) https://www.alodokter.com/hati-hati-membakar-sampah-bisa-membahayakan-kesehatan diakses 14 agustus 2021.

Tim Fresh Water and Fisheries WWF Indonesia- Central Sumatra. (2017). Water Quality Monitoring of Subayang River And Environmental Education In Bukit Rimbang- Baling Wildlife Reserve. tidak dipublikasi.

Tim Fresh Water and Fisheries WWF Indonesia- Central Sumatra. (2018). Water Quality Monitoring of Subayang River And Environmental Education In Bukit Rimbang- Baling Wildlife Reserve. tidak dipublikasi. 
Tim Fresh Water and Fisheries WWF Indonesia- Central Sumatra. (2019). Water Quality Monitoring of Subayang River And Environmental Education In Bukit Rimbang- Baling Wildlife Reserve. tidak dipublikasi.

Tim Fresh Water and Fisheries WWF Indonesia- Central Sumatra. (2020). Water Quality Monitoring of Subayang River And Environmental Education In Bukit Rimbang- Baling Wildlife Reserve. tidak dipublikasi.

WorldWide Fund For Nature (WWF). (2014). Water Scarcity. https://www.worldwildlife.org/threats/water-scarcity diakses 20 Februari 2021 